\title{
Video-based feedback on student assessment: scarily personal
}

\author{
Michael Henderson and Michael Phillips \\ Faculty of Education, Monash University, Australia
}

\begin{abstract}
Assessment feedback is an important part of students' learning experiences; however, textbased feedback has limitations. This article proposes an alternative in the form of individualised video recordings of the lecturer discussing each assignment. This research reports on 126 undergraduate and postgraduate students' reactions to 5-minute videos recorded by their teachers. The findings confirm that the majority of students valued the video feedback over text-based forms. In particular, video-based feedback was reported by students as being individualised (specific) and personalised (valorising identity and effort); supportive, caring and motivating; clear, detailed and unambiguous; prompting reflection; and constructive, which led to future strategising. Several potential weaknesses were also identified, including an initial anxiety about watching the videos, and the difficulty in matching the comments in the video-based feedback to the text-based assignment. Like the students, the teachers also reported that they valued the video feedback process, particularly in terms of being more time-efficient, facilitating quality especially in the form of feed forward comments, and rejuvenating teacher enthusiasm. The article concludes with implications for future research.
\end{abstract}

\section{Introduction}

There is a strong consensus in the research literature that feedback is important, with some authors arguing that it is inseparable from the learning process (Orsmond \& Merry, 2011) and that high quality feedback is the most powerful single influence on student achievement (Brown \& Knight, 1994; Hattie \& Timperley, 2007). The literature has also shown that feedback is a broad term and that both its design and influence greatly depend on the context, such as the agents involved (e.g., teacher, peer, and self), learning contexts (e.g., early childhood, tertiary, and military), focus (e.g., task, process and selfregulation), purposes (e.g., summative, formative, continuous, self, product, process, and diagnostic) and modes (e.g., text, oral, demonstration, and more recently video) (e.g., see Bailey \& Garner, 2010; Boud, Cohen, \& Sampson, 1999; Dochy, Segers, \& Sluijsmans, 1999; Falchikov, 1995; Hattie \& Timperley, 2007; McConnell, 2006; Race, Brown, \& Smith, 2005; Stefani, 1994).

In light of this significant body of literature, it is then somewhat surprising to find that there is no clear agreement of how feedback, including summative assessment feedback, should be designed. Moreover, despite video being available for more than 2 decades as a mode of assessment submission in schools and universities, there has been very little research investigating the value and design of video-based assessment feedback. This gap is particularly interesting when compared with the small but growing body of literature around digital audio and screencasting feedback mechanisms. Within this context, we provide a synthesis of effective principles when creating assessment feedback artefacts (e.g., text, video), offer a comprehensive review of research on video-based feedback and then report on how we have designed video-based feedback as well discuss our students' reactions and our own insights into the process and implications.

\section{Assessment feedback}

The literature clearly indicates that assessment feedback is important and is distinct from other forms of feedback such as in-class feedback (e.g., see Biggs, 2003; Boud, 2000; Costello \& Crane, 2010; Crook et al., 2012; Gibbs \& Simpson, 2004; Juwah, Macfarlane-Dick, Matthew, Nicol, \& Smith, 2004; McConnell, 2006; Race et al., 2005). Critically, the literature takes the view that to be effective, feedback needs to be more than a number or letter grade, and provide "qualitative information" about performance (Joint Information Systems Committee [JISC], 2010, p. 56). Feedback is a "consequence of performance" (Hattie \& Timperley, 2007, p. 81) and is central to students' orientation to learning (McConnell, 2006). Feedback contributes to the quality of student experience (which is a particular concern of a postcompulsory education market), improves motivation, and facilitates students' development and improved future performance (Costello \& Crane, 2010; Duncan, 2007; Higgins, Hartley, \& Skelton, 2001; Lizzio \& 
Wilson, 2008). Hattie and Timperley (2007) point out that when feedback is combined with more of a correctional review, the "feedback and instruction become intertwined" (p. 82) and becomes inseparable in the learning process (Duncan, 2007).

Despite the literature agreeing on the importance of assessment feedback as part of the learning process, the same body of literature also points out that many students do not value the feedback comments but simply skip to the grade (e.g., see Bailey \& Garner, 2010; Crisp, 2007; Higgins et al., 2001; Orsmond \& Merry, 2011). Indeed, some students "do not even bother to collect their work once it has been assessed, preferring to receive their grades by notification from the examination boards” (Duncan, 2007, p. 271). Even if students do read the feedback, some researchers have argued that they do little with it (Higgins et al., 2001), resulting in lecturers complaining that the many hours spent in providing feedback feels like wasted effort (Crisp, 2007).

In order to improve the value (and arguably thereby the valuing) of feedback, researchers have proposed a variety of design characteristics. In their own substantial work, Boud and Molloy (2013) argue "there are many strategies that can considerably enhance the positive impact of feedback ... and there are many options for what we can usefully do" (p. 1). However, while there are many options, not all are specifically relevant to the design and creation of feedback artefacts (e.g., written text, video) by educators. For example, Evan's (2013) extensive literature review of assessment feedback in higher education is a significant contribution to the field, synthesising 23 general principles of effective feedback. However, not all of the principles are relevant to this study, for example, their advice about peer feedback. Another notable contribution to the field has been Nicol and Macfarlane-Dick (2006) who, specifically considering formative and self-regulated learning, devised seven principles of feedback design. While all seven principles are valuable, they are not all specifically relevant to the task of educators creating feedback artefacts for summative assessment. Consequently, the authors have synthesised from a broad literature review a guiding set of eight principles relating to the design of teacher-created feedback artefacts on summative assessment: be timely; be clear (unambiguous); be educative (and not just evaluative); be proportionate to criteria/goals; locate student performance; emphasise task performance; be phrased as an ongoing dialogue rather than an end point; be sensitive to the individual (a more detailed review of the literature and explanation of the synthesis of design principles can be found in Henderson \& Phillips, 2014).

Although the guiding principles have been synthesised from the research literature, it is evident that trying to apply them all at the same time through text-based feedback, while not impossible, would be complicated and time consuming, particularly in large class contexts. Indeed, educators are constrained by the amount of time they have to provide individual feedback as well as the need to be timely (both as best practice and institutional requirements). As a result of the tension between the desire to provide effective feedback and our own limitations in time, the authors intuited the potential of video as an alternative to text-based feedback. However, despite the considerable body of literature dealing with feedback, surprisingly little attention has been given to the modality of assessment feedback, such as video recordings of teachers responding to student assessment.

\section{Video-based assessment feedback}

The use of video recordings of the educators as part of assessment feedback in academic studies has received little consideration in the research literature. While video as a feedback mechanism is well established in cognitive behavioural fields such as working with children with autism (e.g., Bellini \& Akullian, 2007) and improving athlete performance (e.g., Ives, Straub, \& Shelley, 2002), it is more difficult to find empirical studies relating to the use of video-based feedback in response to academic tasks. Hattie and Timperley's (2007) meta-analysis noted that "video or audio" feedback had an average positive effect size of 0.64 . However, they failed to explain what they mean by video feedback or identify the source of the meta-analysis. Personal correspondence with Hattie (November 16, 2012) clarified that the results in their meta-analysis were drawn from studies of computer assisted learning (CAL). As such, the results are not directly relevant to our work since we are dealing with videos recorded by educators in response to student assessment, as opposed to typical CAL applications of video cues in response to student actions. 
A literature review on the use of technology in feedback by Hepplestone, Holden, Irwin, Parkin, and Thorpe (2011) made no reference to video-based feedback. However, in a similar review of technologies for learner-centred feedback, Costello and Crane (2010) identified video as having some benefits, but their conclusion is based on two sources, only one of which was based on empirical evidence (Parton, Crain-Dorough, \& Hancock, 2010), while the other (Denton, Madden, Roberts, \& Rowe, 2008) is itself making a passing reference to a much older article from 1997 (Hase \& Saenger, 1997). After a significant search of the literature only a small number of journal articles were found that reported on empirical research about video-based assessment feedback. However, most of those articles were focused on generic or whole class feedback on students' performance, and agreed that such videos provided a positive and rich feedback experience for both students and staff (Abrahamson, 2010; Cann, 2007; Crook et al., 2012; Crook et al., 2010).

Only one research paper in the last decade was found to deal with individualised video-based assessment feedback. Parton et al. (2010) conducted a study in which an instructor provided 12 graduate level students with written feedback on their first assignment, a combination of written feedback and a video explaining the remarks made on the hard copy of the second assignment, and only video-based feedback on the third. The videos were approximately 5 minutes in length, and created through the use of a Flipcamera (video camera with USB connection). However, no further detail was provided about the design of the video-based feedback, such as the use of feed forward, or purposeful leveraging of any particular affordance of the media. The instructor reported that she was able to "convey much more through the video than through the written comments especially in terms of encouragement and praise for parts of the assignments which she might have simply marked 'good job' on a hardcopy" and that she could "elaborate and give more detail than she has been able to previously" (Parton et al., 2010, p. 3). Like the studies of non-individualised videos (Abrahamson, 2010; Cann, 2007; Crook et al., 2012; Crook et al., 2010), the students found the feedback easier to understand when video was used. A striking outcome of the project was the clear indication that the video-based feedback resulted in the students feeling they had a closer connection with their instructor (from 25\% in assignment 1 to $91.7 \%$ in assignment 3). This is despite a constant $91.7 \%$ of students across the three assignments indicating that they felt their instructor cared about their performance. As a consequence Parton et al. (2010) concluded that the "primary benefit of the videos appears to be in developing the bond between instructors and students" (p. 5). However, they note that the small number of participants is a major limitation to the study and that this line of inquiry needs to be researched further in larger classes and across instructors.

\section{Research method}

This research has evolved out of a scholarship of teaching practice. The authors of this paper taught postgraduate and undergraduate classes in the field of education in which the feedback on the major assessment item (a negotiated project or essay) was provided through a short video (approximately 5 minutes). The use of video-based feedback was not implemented initially as part of a research project, but as a teaching strategy that we intuited as having the potential to increase student understanding and satisfaction.

In the first two instances of this strategy being implemented $(2008,2010)$ we were surprised by the number and positive tone of unsolicited emails from students about the impact of the video (see Table 1). Despite a combined 25 years of teaching experience we had never witnessed this kind of response to textbased feedback. However, we were cautious that the comments were unsolicited and thereby potentially more likely to be positive in nature. On the third iteration (2011) we invited students to email us about their positive as well as negative reactions to the videos (however, 3 students had already responded before our invitation was sent; see Table 1). Again, there was an unequivocally positive response. During this time we also shared our experiences (via presentations and a video blog) with teaching colleagues, who subsequently reported positive outcomes from using the strategy. By this time it had also become clear that there was a paucity of research literature on this topic. Consequently we gained permission from the research ethics committee to use the emails and forum posts from previous years as well as implement a survey and interviews to both postgraduate and undergraduate classes. The aim was to clarify further the key affordances, constraints and other implications such as impact on self-efficacy beliefs. 
Table 1

Participant data

\begin{tabular}{|c|c|c|c|c|c|}
\hline \multirow{2}{*}{ Class } & \multirow{2}{*}{ Year } & \multirow{2}{*}{ Enrolled } & \multicolumn{2}{|c|}{ Email or forum posts } & \multirow{2}{*}{ Survey } \\
\hline & & & Unsolicited & Solicited & \\
\hline \multirow{5}{*}{ Postgraduate } & 2008 & 19 & $11(58 \%)$ & - & - \\
\hline & 2010 & 14 & $5(36 \%)$ & - & - \\
\hline & 2011 & 19 & $3(16 \%)$ & $7(37 \%)$ & - \\
\hline & 2012 & 13 & $4(31 \%)$ & - & $8(62 \%)$ \\
\hline & 2013 & 46 & $14(30 \%)$ & - & $25(54 \%)$ \\
\hline \multirow{4}{*}{ Undergraduate } & 2012 & 21 & - & - & $16(76 \%)$ \\
\hline & 2013 & 41 & $8(20 \%)$ & - & $25(61 \%)$ \\
\hline & & Subtotal & $45(36 \%)$ & $7(5 \%)$ & $74(59 \%)$ \\
\hline & & Total & & 126 & \\
\hline
\end{tabular}

The evolution from teaching strategy to research project over several years means that the nature of the data is messy and difficult to compare (e.g., unsolicited and unstructured emails compared with survey responses). In preparing this paper there is some pressure to simplify the project by excluding the emails. However, they provide a valuable unstructured response that has not been influenced by research instruments, such as the wording of questions in the survey. Therefore, due to the complexity of data, and the fact that this was an exploratory research project without hypothesis or goal we adopted a grounded theory approach with the aim of revealing possible themes and patterns that may inform further research. Open coding of the documents created by students and teachers (email, discussion forum posts, videos, presentation materials and lecturer observations and video blog) as well as the student survey led to the development of categories of positive and negative issues in design and implications which are presented in this paper.

\section{Video-based feedback design}

The videos were created by one teacher using a webcam (Logitech Quickcam Pro) and video recording software (Logitech and sometimes Windows Movie Maker) and by the other teacher with an iPhone (propped up to reduce camera movement). The simplicity of the process meant that we could easily record the videos wherever we marked the assignment, at work or home. It also meant that the videos were immediately available and in a format ready for uploading without any editing or post-production work.

The cameras were focused on the heads and shoulders of the teachers with enough space in the frame to allow some movement and capturing of hand gestures (see Figure 1). There was no need for high quality video resolution so long as the students could see the facial expressions and clearly hear the teacher. Keeping the video files sizes small enough to upload (and download) quickly was an important consideration. We found that 5 minutes is a suitable length to provide detailed feedback while also maintaining manageable file sizes for uploading and downloading. 


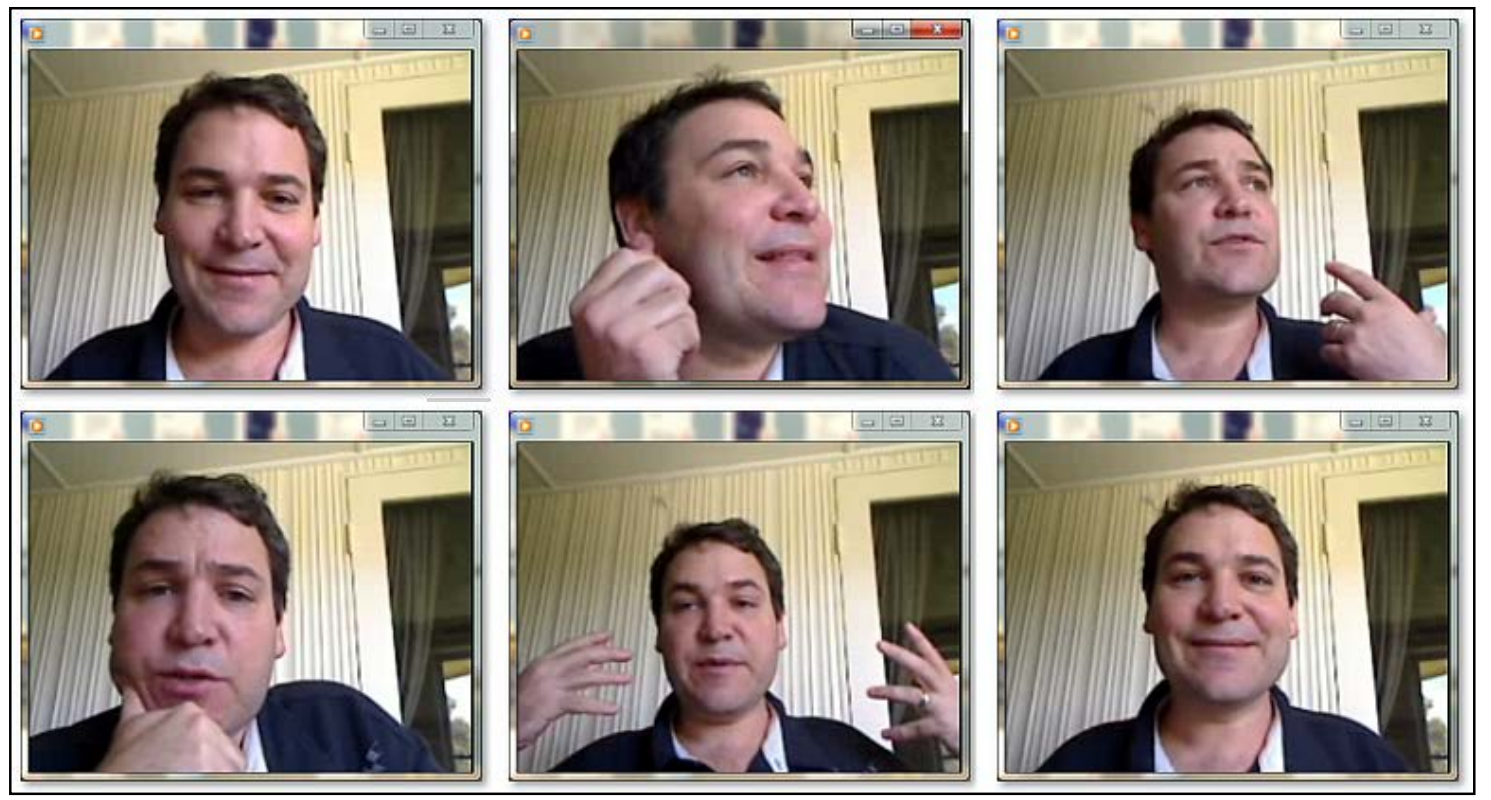

Figure 1. Frames from a feedback video spanning the 5 minutes

In our courses, video feedback was provided for the final assignment (worth $50 \%-60 \%$ of the semester's grade). The students had already received detailed written feedback on their first assignment. The videos were generally recorded immediately after the assignment was read, and while notes were made on the assignment as prompts no script was written. The proximity of the recording to when the assignment was read, meant the comments were specific, the advice relevant and the language had a sense of immediacy. This also meant that our time was not wasted making copious notes to recall the specific details of individual assignments. We rarely re-recorded and never edited videos as this would make the process too time consuming and ultimately unsustainable for larger or multiple classes. This meant that the videos invariably contain pauses, ums, and even moments where we had to rephrase our comments because we realised we had not been clear enough or were momentarily distracted. The recorded videos along with the grades were then uploaded to the grade book in the student learning platform (Moodle).

The two lecturers used the same narrative structure in their video-based feedback (confirmed through an analysis of 10 videos produced by the lecturers). The narrative structure is detailed in Table 2. The structural elements, or parts of the narrative, are similar to what the lecturers normally included in their written feedback (based on an analysis of 20 assignments with text-based feedback by the lecturers). However, there were some striking differences in volume of detail as well as emphasis. The videos were approximately 5 minutes in length, whereas the text-based feedback comments (not including in-text edits) on similar assignments were the equivalent of less than 1 minute of talking. The video-based feedback gave more time to establishing and building on a relationship with students, emphasised student conceptual engagement with time given to considering future performance and growth. In contrast, the text-based feedback emphasised textual issues and the structure and justification of arguments in the assignment with less time spent on relational work and how to extend ideas and critical thinking. 
Table 2

Structural analysis of video and text-based feedback

\begin{tabular}{ll}
\hline Structure & Video-based feedback \\
\hline Salutation & Conversational/informal salutation: "Hi Lee” \\
\hline Relational work & $\begin{array}{l}\text { Recognition and valuing of the student including personal circumstance and } \\
\text { history. This both draws on and reinforces the pedagogical relationship } \\
\text { between teacher and student. This might include a sympathetic comment } \\
\text { (e.g., "I know you have been quite ill lately and I am truly impressed that } \\
\text {...), appreciation of effort of previous drafts (e.g., "I can see you have } \\
\text { made a lot of changes to your introduction”), reaction to quality or other } \\
\text { aspect of submission (e.g., "Thank you for submitting ... I can see how } \\
\text { much effort ...”). }\end{array}$ \\
\hline
\end{tabular}

Evaluative summary

General statement of evaluation, not necessarily the grade or mark. Very few of the videos specifically stated the grade, which was indicated to the students before they opened the video. A general evaluative statement here provided a chance to highlight the overall strength and weakness of the assignment before dealing with the more specific issues. For instance, "The essay is very strong in its theoretical approach ... need work in ..." and "I thoroughly enjoyed ... but there are some issues we need to talk about, namely ...”

Textual issues

Briefly describing the nature, patterns and extent of textual issues (e.g., grammar, punctuation, flow, formatting) in this assignment, occasionally with one or two specific examples. This segment of the feedback is short but generally included the same volume of comments about textual issues as the final evaluative notes in the text-based feedback (but not the specificity of the in-text edits).

Commenting on the substance of the assignment with an emphasis on feed forward.
Engaging with the conclusions, arguments, logic, justification, and literature included in the assignment. Commenting on strengths, weaknesses, flaws, gaps, creativity and insights. Importantly, comments were phrased to emphasise how students can improve their grades in future work and how they can extend their thinking about the substance of the assignment. This might include examples of alternative arguments, additional literature and different ways to think or approach the topic. Usually 2 to 3 issues were discussed in detail, regardless of result.

Valediction and invitation This is largely relational work. Usually involving use of student name, coupled with congratulations or commiseration over result or other interpersonal validation, such as, best wishes for future studies / holiday.

Importantly, this structural component included an invitation to contact the lecturer to "continue the discussion” of this feedback and future work.

\section{Findings}

The students were overwhelmingly positive about the video-based assessment feedback. An interesting phenomenon, which largely prompted this study, was that a surprising proportion of the students provided unsolicited responses to the video feedback in the form of direct emails to the teachers or via the discussion forums. In total there were 52 (unsolicited and solicited) comments of which 51 (98\%) were unequivocally positive about the video-based feedback, using phrases such as personal, authentic, supportive, stronger and clearer. The single student who expressed a preference for text rather than video feedback explained that he strongly felt a sense of personal connection with the assessor because of the 
video, but also felt it was better suited to formative assessment where the educative and feed forward comments would be more useful. Clearly, the student recognised the educative value of the video-based feedback but it reminded us of the tension between the perceived function of formative and summative assessment. Nevertheless, it is our contention that summative feedback should also be educative. The themes emerging from the emails and forum posts are discussed in greater depth along with the survey data.

Overall the survey respondents were also in favour of the video-based feedback. Table 3 shows that 67 (91\%) of the respondents stated that we should continue with the video feedback method. This is despite 4 of those students indicating that they did not like receiving the feedback in this way. In contrast, only 7 (9\%) of the respondents stated that we should not continue with the video feedback. Their reasoning is indicated in the notes to Table 3, but can be described as either a perception that the video was confronting in comparison with written feedback or that the video could not be "skimmed" like text. However, these same comments were also made by respondents who felt we should continue with video feedback. When comparing variables such as gender, degree level, or English as Second Language, there was no discernable relationship with preference for video or text-based feedback. We recommend that further research needs to be conducted to explore if there are ways to predict student preference for modality feedback, such as video, audio or text.

Table 3

Survey respondent preferences of mode of feedback

\begin{tabular}{|c|c|c|c|c|c|c|}
\hline & & \multirow{2}{*}{\multicolumn{4}{|c|}{ Did you like receiving video feedback? }} & \multirow[b]{4}{*}{ Total } \\
\hline & & & & & & \\
\hline & & \multicolumn{2}{|c|}{ Yes } & \multicolumn{2}{|c|}{ No } & \\
\hline & & $\begin{array}{l}\text { We } \\
\text { should } \\
\text { continue } \\
\text { with video } \\
\text { feedback } \\
\end{array}$ & $\begin{array}{l}\text { We should } \\
\text { not continue } \\
\text { with video } \\
\text { feedback }\end{array}$ & $\begin{array}{l}\text { We } \\
\text { should } \\
\text { continue } \\
\text { with video } \\
\text { feedback } \\
\end{array}$ & $\begin{array}{l}\text { We should } \\
\text { not continue } \\
\text { with video } \\
\text { feedback }\end{array}$ & \\
\hline \multirow{5}{*}{$\begin{array}{l}\text { Mode } \\
\text { preference }\end{array}$} & Strongly prefer video & 17 & - & - & - & 17 \\
\hline & Prefer video & 16 & - & - & - & 16 \\
\hline & Equal & 25 & - & 2 & - & 27 \\
\hline & Prefer text & 5 & 1* & 1 & $1 * *$ & 7 \\
\hline & Strongly prefer text & - & - & 1 & $5 * * *$ & 6 \\
\hline \multicolumn{2}{|l|}{ Total } & 63 & 1 & 4 & 6 & 74 \\
\hline \multirow{2}{*}{\multicolumn{7}{|c|}{$\begin{array}{l}\text { * Despite having a positive experience the student was concerned that if the grade was low it would be a very } \\
\text { confronting situation for students to receive their comments "in person". } \\
\text { ** Found video slow to "read" and desired the ability to "skim" the comments }\end{array}$}} \\
\hline & & & & & & \\
\hline \multicolumn{7}{|c|}{$\begin{array}{l}\text { *** Three wanted text to refer back to and found video could not be skimmed easily. Two felt it was confronting to } \\
\text { receive feedback in video format. }\end{array}$} \\
\hline
\end{tabular}

It is common practice in Australian universities for all students across all courses to be surveyed with regards to their degree of satisfaction with each subject according to a variety of measures. All of the classes in this study demonstrated improved results in their student evaluation surveys relating to the item "usefulness of feedback". Although the student evaluation surveys refer to the class across the entire semester (and not just the feedback of one assignment) it is felt to be generally confirmatory of our approach that all of the classes across the 5 years scored an average median of 4.7 (lowest median 4.4, and highest 4.9) in comparison with the university-wide median of 3.9 (5-point scale with 3 as neutral and 5 as strongly agree). This is a tenuous link to make; nevertheless, as evaluation surveys are a feature of the higher education landscape, it is worth mentioning if only to raise it as a suggestion for future research.

Although the data in this study has been collected from a variety of sources, it is abundantly clear that the majority of students appreciated the use of video-based assessment feedback. It can be argued that the emails and forum posts are more likely to feature positive comments since the data are not anonymous. However, the anonymous surveys also indicated a strongly positive response. In trying to understand the perceived strengths and weaknesses, we have analysed the data for patterns and deviations to those 
patterns. As a result, seven recurring themes were identified (each theme is represented in at least $20 \%$ of the email or survey data). These themes include five strengths and two potential weaknesses.

Five of the themes indicate perceived strengths of video-based assessment feedback:

(1) individualised and personal: specific and valorising identity and effort

(2) supportive: perceived as caring and felt to be motivating

(3) clear: detailed and unambiguous

(4) prompting reflection on work done, process and thinking in terms of success criteria

(5) constructive (useful): prompting consideration of future work, process and thinking.

In addition to these perceived strengths, the data suggest two potential weaknesses:

(1) initial anxiety about seeing the assessor's face while receiving feedback (particularly when they feel that may be receiving negative feedback)

(2) matching feedback to assignment: sometimes effort is needed to find the specific examples in the assignment that relate to the video comments.

The frequency of these themes appearing in the data is represented in Table 4. The table is a product of analysing the email, forum and survey responses. In addition, the five themes of perceived benefits were identified in the 2012 iteration of the survey and, consequently, 5 Likert-scale questions were included in the 2013 survey. The two weaknesses were not identified as themes until the aggregate 2012 and 2013 data were analysed. Future iterations will need to validate these themes.

Table 4

Themes emerging across email, forums and survey data

\begin{tabular}{llccc} 
& & $\begin{array}{l}\text { Email and } \\
\text { forum posts } \\
(2008-13, \\
N=52)\end{array}$ & $\begin{array}{l}\text { Survey open- } \\
\text { ended responses } \\
(2012-13, N=74)\end{array}$ & $\begin{array}{l}\text { Survey Likert scale } \\
\text { mean (1 strongly } \\
\text { disagree to 5 strongly } \\
\text { agree) }(2013, N=46)\end{array}$ \\
\hline \multirow{2}{*}{ Benefits } & $20(38 \%)$ & $36(49 \%)$ & 4.5 \\
\cline { 2 - 5 } & $\begin{array}{l}\text { Individualised and personal } \\
\text { Supportive (caring and }\end{array}$ & $22(42 \%)$ & $20(27 \%)$ & 4.5 \\
\cline { 2 - 5 } & $\begin{array}{l}\text { Clear (detailed and } \\
\text { unambiguous) }\end{array}$ & $16(30 \%)$ & $38(51 \%)$ & 4.1 \\
\cline { 2 - 5 } & Prompting reflection & $18(34 \%)$ & $8(11 \%)$ & 4.2 \\
\cline { 2 - 5 } Concerns & Constructive (useful) & $25(48 \%)$ & $13(18 \%)$ & - \\
\cline { 2 - 5 } & $\begin{array}{l}\text { Initial anxiety } \\
\text { Matching feedback to } \\
\text { assignment }\end{array}$ & $1(2 \%)$ & $25(33 \%)$ & - \\
\hline
\end{tabular}

\section{Strengths of video-based feedback}

The data revealed five strengths, that is, students reported positive attributes as consequence of the videobased feedback. However, it should not be assumed that the strengths are due to the media itself, but should be considered a combination of the media, design of the use of the media (see Table 2) and the eight guiding principles presented in the literature review. Further analysis needs to occur to accurately distinguish the variables and effect.

Individualised and personal

Students clearly indicated that they found the feedback to be individualised (specific to them as individuals) but also, importantly, that the feedback was felt as personal. One student explained: 
Text feedback is far too easy to construct. With video, I think that the assessor needs to have read the work in some detail and have a good understanding of the content in order to put meaningful verbal sentences together. Comment banks are not an option.

The basis of this student's reasoning is debatable. It could be argued that a marker might be able to get away without reading the work in detail and could indeed be drawing on a comment bank to provide substance for their video. However, the student's quote does reveal a frequently reported perception by students that the video-based feedback represented not only a specific and individualised response to their work, but was also personal, that is, valorised their identity and effort as students. For example, students reported that the degree of individualised comments combined with the richness of video-based feedback "makes you feel valued as a student," "makes me feel like I'm an individual and not just a name on the enrolment list", and in the case of off-campus students, "feel like part of the class." Direct comparisons with text-based feedback were made by many students emphasising this sense of valorisation. For example:

What I love most from video feedback is that it is really personalised. I mean... If the feedback is in written form, a student can be sceptical of the content (because s/he might think that some elements of the feedback might also appear in their peers' feedback).... But in video feedback, it seems that you really talk to me, and give me some feedback on my writing.

Students felt that the lecturer knew and recognised them ("you really talk to me"). It is likely that this effect is not only a product of the volume of comments, the rich cues afforded by the media, but also the way in which the videos were framed (lecturer's face, rather than screencast). The sense of presence, of the lecturer speaking directly to the learner, was a common theme across 44\% of the responses (56 of 126 email, forum and open-ended survey responses). Examples are "It felt very personable, it was like sitting down having a face-to-face conversation (even though I could not respond!)” and "It was very personal. It was like I was in the same room as the person giving the feedback.” Indeed, this effect was felt acutely by some: "I was a little scared to actually hear Michael's comments. For some reason I almost felt embarrassed. It was like having the conversation... in person.” The issue of anxiety in receiving videobased feedback is explored later in the article, but it is useful to note here that students reported experiencing the video feedback in more visceral terms than text-based feedback.

A surprising finding was that students reported that they felt the feedback to be "real", "honest" and "authentic". This was invariably linked with their sense of the feedback being personal. For example, "I liked the video feedback because it felt personal. I felt a higher degree of authenticity given that I could see the person's face... was able to read and interpret visual signs and cues.” As this quote suggests, the framing of the video (lecturer's face) and the rich cues afforded by the media reinforced the salience of the feedback. This was clearly exemplified by a student who claimed the video "seemed like face to face feedback where you get information directly from the horse's mouth and pay attention!” Another student pointed out that the feedback "was given in a very genuine and honest manner (body language) which I found beneficial." However, it is unlikely that the media or framing of the recorded image were solely responsible for the students' reactions. We suggest that the unscripted nature of the content (see section on video-based feedback design) and the feedback content design (see Table 2), with its emphasis on relational work and feed forward, would have contributed to the students' sense of lecturer sincerity and feedback integrity. This was indicated by one student who interpreted the relational and invitational components of the video (see Table 2) as contributing to the "honest and frank spirit" of the feedback. However, the implications of this perceived authenticity, and the link to the media affordances and feedback design need to be further explored in future research.

Supportive: perceived as caring and felt to be motivating

Students felt supported by the lecturer, and in particular, that the lecturer was caring and motivating. This theme was reported in $42 \%$ of the email and forum posts, and $27 \%$ of the open-ended survey responses (see Table 4). In addition, the 2013 survey $(n=46)$ confirmed the theme with a mean score of $4.5(4=$ agree, 5 = strongly agree). This theme is clearly linked to the previous theme (individualised and personal), in particular to the social presence (for a discussion of social presence theory see Short, Williams, \& Christie, 1976) conveyed by the lecturer through the rich cues afforded by the media, and 
through the feedback content design (see Table 2), namely the relational work, feed forward (perceived as an interest in the student's welfare), and invitational conclusion.

Students noted that the video enabled them to interpret the feedback in positive and constructive ways. For instance, a student explained that "the tone of voice and the expression was very friendly and supportive" and as a consequence she interpreted the feedback in a "positive" way that she may not have done with the same feedback in a text-based form. Another student explained how the detail, personalisation, and emphasis on feed forward resulted in feeling "motivated to pursue for more and strive for excellence!" She explained that this was in contrast with her typically critical reaction to textbased feedback.

The video-based feedback also heightened social presence: "With all the facial expressions, gestures, and eye contact, the feedback seems to be more 'alive'. And I like it.” This sense of being present has already been described in the previous theme as facilitating a sense of personalisation. However, it was also commonly linked in the data with reports of feeling supported and motivated. For example:

During the video I was surprised at how immediate it felt, and how I was provided with the opportunity for a detailed discussion of the solution. The emotion and energy conveyed during the video was inspiring and motivating.

The perceived sincerity involved in creating the videos also encouraged the students to see the feedback as a caring response: "I think it demonstrates a higher level of emotional investment [from the lecturer] in the assessment." This in turn appeared to stimulate emotional responses from the students, from "excitement" to "guilt"; for example, a student reported that the detailed feedback and sincerity of the lecturer resulted in her being "happy with my results although I feel guilty for not doing as well on the second task.”

\section{Clear: detailed and unambiguous}

A strong theme in the data was that the video-based feedback was perceived as being rich in detail. For example, "I think this feedback was far more comprehensive than any written feedback that I received." In coming to understand student responses, it may be worth considering that an analysis of a typical 5minute video by the researchers revealed a total of 625 words. This is substantially more than the researchers would normally include in text-based feedback, including in-text and end-of-paper comments. While this volume is obviously dependent on context, including speaker and language, the overall point is still valid. In terms of volume of wordage a recording of spoken feedback is highly efficient. However, researchers such as Crisp (2007) and Brockbank and McGill (1998) caution that large volumes of feedback may be redundant, with only a proportion of the feedback being received by the student. Although this was not commented on by students in this study, it may be a worthwhile avenue for future research to identify if there is an optimal volume of detail.

When analysing the data relating to clarity of the feedback, it became apparent that students not only talked about degree of detail (particularly in comparison to written feedback), they also indicated that the feedback was clear in terms of being unambiguous. The students' data particularly highlighted the auditory and visual cues afforded by the video recording, for example: "The visual element provided me with a stronger, clearer understanding of what your feedback meant". These rich multimodal cues also had an impact on how the message was received:

I think the whole notion of giving feedback - constructive or not - can be tricky and sometimes misinterpreted... Being able to 'see' the feedback made the comments seem more positive where as if it had been written I might have interpreted it differently.

The affordance of video to reduce ambiguity, and be perceived as "stronger, clearer" particularly in comparison with text-based feedback, is explained by media richness theory (Daft \& Lengel, 1986). Leaner media such as text cannot convey powerful cues such as tone, pace, gesture, expression. Media richness theory posits that interactions involving complex or fraught issues are best conveyed through richer media (such as telephone, video and in-person) to reduce ambiguity. As one student noted: "The verbal feedback eliminated the horrible connotations associated with the 'red pen'." In this study a large 
proportion of students perceived the video as providing unambiguous detail, but it is worth noting the potential for future research to validate if the message being conveyed is the same as being received.

An implication of media richness theory is that face-to-face feedback would be considered richer than video recordings. This is because the content of the feedback could be adapted to suit the particular context and in response to the recipient's verbal and nonverbal cues (e.g., frown, nod, request for clarification). However, students in this study reported that they appreciated the "ability to repeat/pause" and that they revisited the feedback, and "got more of the message as I played the feedback file back over time.” Being able to revisit feedback is not afforded by face-to-face meetings unless they are recorded in some way. Moreover, one of the students raised an interesting point: "Video allows time to absorb and think reflectively rather than focus on a two way conversation and what you are going to say next.” In this instance, the use of video-based feedback appears to have increased the richness of the message, while at the same time avoiding challenges of performance anxiety.

\section{Prompting reflection on work done, process and thinking in terms of success criteria}

The students not only reported that the video-based feedback was personal and clear, but also that it led to reflection of the work they did in terms of assignment criteria and other performative goals. This theme was reported in $34 \%$ of the email and forum posts but only $11 \%$ in the open-ended survey responses (see Table 4). However, the 2013 survey $(n=46)$ confirmed the theme with a mean score of $4.2(4=$ agree, 5 = strongly agree). Importantly, students' comments revealed reflection not only in terms of the quality of the product itself (the assignment) in relation to the criteria but also on the process and thinking they used to create the product. Sadler (1989) argued that this is an important function of feedback: to elicit in the learner an understanding of the task or process of learning required to fill the gap between what is understood and what is aimed to be understood. In this study students indicated that the feedback "helped me in evaluating my work more effectively", "to absorb and think reflectively" as well as to "understand what I was doing wrong". One student commented: "As a result of customised video feedback, I felt more confident about my current efforts and realised the weak points of my writing and how they can be improved in future." The value of the feedback in terms of being perceived as useful and prompting future strategies is explored in the next section.

\section{Constructive (useful): prompting consideration of future work, process and thinking}

Students felt that the feedback was constructive in the sense of being something they could use to improve their future performance. This theme was reported in $48 \%$ of the email and forum posts and $18 \%$ of the open ended survey responses (see Table 4). The 2013 survey $(n=46)$ confirmed the theme with a mean score of 4.3 ( 4 = agree, $5=$ strongly agree). This was also confirmed by the fact that students not only talked about the value of the feedback in general terms, such as to "help to improve and not to repeat mistakes" but also revealed that they were specifically responding to the feedback and talking about how the feedback had given them insight into strategies to approach future tasks. For example, one student commented that the feedback "gave me direction on where to take this writing in the future and how to approach it. It was impressive... it gave me insight for the next writing task.” It was also apparent that students were actively synthesising the feedback and forming their own future strategies. For example, a student whose feedback included a discussion about the need to substantiate instructional design choices reported an actionable strategy: "I'll be sure to include... the theoretical considerations behind my design." The significance of such an outcome is explained by Hattie and Timperley (2007), who argue that feed forward is particularly important especially when it leads students to new ideas about the process they use to produce work, and the thinking involved in that process.

It is doubtful that feed forward is a by-product of the video media itself. However, we argue that the efficiency in video-based feedback, combined with the specific design of the feedback (see Table 2), has resulted in considerable more time devoted to discussing what students could pursue in future work, including suggestions about strategies and analytical thinking.

\section{Potential weaknesses}

The data reveals a number of potential problems with the video-based feedback. Two students reported that their computer/device could not play the video and they had to find a different device. This highlights the need to remind students about media plug-ins for computer systems, but also reminds us that mobile devices, such as iPhones, iPads, and tablets may have specific media requirements. A different concern 
was reported by one student, who noted that video-based feedback is not conducive to open office environments in which there is little privacy to listen to the feedback. In all three cases the students reported that they were able to resolve the situation by choosing a different device or time to access the feedback.

A larger number of students $(n=26,21 \%)$ identified that they were initially anxious about playing the video. For example, "Before I opened the link, I was anxious and worried. Once I started to watch it I thought that is was wonderful as the response was quite detailed. It gave positive attributes to work and discussed challenges." While it can be assumed that most students would feel a degree of trepidation at looking at their grade, it is important to point out that the students in this project already knew their grade before accessing the video feedback. One student mentioned that knowing the grade before watching the video "allowed the feedback to be contextualised" but he still "felt nervous." However, the same student reported: "When I began to watch the video I quickly relaxed - the structure of the feedback, focusing on the positive first and then offering opportunities for improvement later worked to ease my nerves." The frequency of students reporting this concern suggests that students do perceive the summative assessment feedback to be consequential, at least in terms of self-esteem and identity. This anxiety can be seen even in students who report that they have received a "good result"; for example, one student explained that the video-based feedback “delved into a personal space that I am not particularly comfortable with” and had to "mentally psych myself up to be ready for some potential criticisms... I wasn't quite ready to be dressed down... I think seeing and hearing it makes it seem more confronting”. However, the same student noted that "to some extent I have probably paid more attention to the video feedback and have taken notes on what I need to do to improve my work.”

A question for future research is to determine if the anxiety reported here is an affective state that is conducive to receiving feedback. However, in all of the reported instances the anxiety was reported as a temporary state, and there was a strong sense of the video-based feedback overall being perceived as supportive and caring (see Table 4). Nevertheless, future research being conducted by the authors is investigating if regularly receiving video-based feedback, coupled with clearer statements of feedback purpose, will help to reduce the initial anxiety.

A final concern reported by 15 students (12\%) was that in some instances they had to spend time searching their assignments to find the particular example being discussed in the video-based feedback. For instance a student reported in the survey:

I think this feedback was far more comprehensive than any written feedback that I have received [to date]. In saying all that though, I did, at times, find it difficult to follow which section of the piece [the lecturer] was referring to, even though he made references to page numbers and sections.

This problem is not surprising since students are being asked to match the feedback video content to their assignment (an essay or project) which they had completed at least 2 weeks earlier. Indeed, it is perhaps surprising that more students did not report this problem. A conclusion can be made that it is important for the video-based feedback to carefully locate any specific examples discussed (e.g., by reference to page number and paragraph). It may also be concluded that video-based feedback is unlikely to be an effective strategy if a high degree of specific reference to the assignment is required. In this case it may be useful to consider providing both video-based feedback as well as comments on the assignment itself. This was suggested by one of the students who stated, the "video format is great as it provides a more holistic approach to feedback. ... But it would be even more beneficial when coupled with a marked-up version as well.” The researchers had originally discarded the idea of providing both annotations and video-based feedback as it was judged to be time consuming, which conflicted with one of the design goals, being sustainable in terms of lecturer workload. This is confirmed by Mathieson (2012), who found that providing text annotation along with screencasting doubled the time it took to provide the feedback and thereby concluded that it is an unlikely strategy for large classes.

Nevertheless, screen capture technologies may provide a useful alternative. Hyde (2013) reported that in her small trial, students were "clear about exactly which section of the work was being referred to" (p. 3). However, the positive outcomes of the video-based feedback reported by our own students suggest that it may be valuable to explore a hybrid in which both the screen and the lecturer are recorded. Screencasts 
which include a small inset video of the speaker is a feature of a number of screencast applications (e.g., ScreenFlow). Nevertheless, we are cautious of recommending screen capture technologies for three main concerns. First, the video of the student work may shift the marker's focus to discussing the minutiae of task performance to the detriment of discussing larger conceptual development. Second, dealing with such detail may increase the time taken for video recording to the point that it is not sustainable in terms of marker workload. Third, the students may suffer from too much content detail as well as cognitive load from too many communication channels (audio, video of face and video of screen). In a separate paper we provide a more extended discussion of the literature and implications surrounding audio and screencasting assessment feedback (Henderson \& Phillips, 2014).

\section{Educator experience: workload and rejuvenation}

A key concern for the lecturers was that the video-based feedback needed to be sustainable. The time and effort it took to create videos needed to be as fast and easy as text-based feedback. When comparing the processes we found that creating the videos was indeed much faster; on average, taking about half the amount of time. A similar finding was reported by Hyde (2013) in relation to screencasting feedback, who noted that it was "much quicker... than paper-based system" (p. 3). When preparing text-based feedback, we would normally make annotations throughout the paper (e.g., in margins) and then write an explanation of the key areas of concern at the end of the essay. In comparison, when preparing the videobased feedback we made quick notes (often just symbolic markers) on the paper as reminders for the video and then recorded the video itself (approximately 5 minutes). In addition to speed, we found the process to be easy: we recorded the video and uploaded the file to the online mark book. However, both of the authors have a high degree of computer proficiency. Nevertheless, the simplicity of the process was also reported by Parton et al. (2010): "this approach is both simple enough to not be a burden on the faculty member, but powerful enough to have a positive impact on students” (p. 5).

It is arguable that the video-based feedback process lacks the volume of detail in relation to grammatical, punctuation and formatting corrections, which may be important for the ongoing development of student writing skills. However, no student reported a sense of loss in terms of such textual corrections. This may be due to the fact that the students had already received detailed written feedback, with annotations, on their first assignment. Nevertheless, it should also be pointed out that feedback relating to textual issues is a feature, albeit with less emphasis, within the video-based method (see Table 2). Finally, there is an argument that while the videos did not include a blow-by-blow account of each grammatical or other textual issue, it did include a commentary on the nature, patterns and extent of textual issues. Such an explanation of critical textual issues, particularly pointing out patterns in their writing and why it is problematic, is arguably more useful than simply circling each punctuation error or even rewriting a sentence for them.

An unexpected aspect of the video-based feedback was the rejuvenation we experienced from engaging with the concepts, issues and structures that are too hard to explain easily in text-based feedback annotations. This positive affect was also noted by Crook et al. (2012) in their research on generic (not individualised) video-based feedback. The move from dealing with the minutiae of text errors and citation problems to being concerned about argument and future directions made the marking process one of intellectual stimulation. Instead of just having enough room to write one or two readings for the student to pursue, we could engage with their idea and expand upon it, and ultimately become creative ourselves. In a blog entry, one of the researchers wryly commented: "I feel like a teacher rather than an editor, and I find myself saying that I almost enjoy marking.” The emphasis on feed forward shifted a perception that the comments no longer felt like an exercise in defending a grade (i.e., justifying the evaluation) but rather providing valuable advice. We approached the marking process with a lack of the characteristic dread or sufferance, and instead experienced, if not joy, at least a sense of purposeful enthusiasm and curious anticipation.

\section{Conclusion}

While there is a growing body of evidence relating to the design of feedback in general, this article offers a synthesis of the literature relating to the specific content design of teacher created feedback artefacts (e.g., text, video). The resulting principles are be timely; be clear (unambiguous); be educative (and not just evaluative); be proportionate to criteria/goals; locate student performance; emphasise task 
performance; be phrased as an ongoing dialogue rather than an end point; and be sensitive to the individual.

In addition, this article offers guidelines on the creation and structure of the video-based feedback, including framing, length, and unscripted nature of the content. The structure was much the same as textbased feedback but placed a larger emphasis on relational work, invitational work, and feed forward (see Table 2).

Finally, the data reveals a strong positive reaction from students. The reaction and the themes were consistent across years, and in different undergraduate and postgraduate classes. In particular, the data reveals five perceived strengths of video-based assessment feedback. First, the students felt the feedback was specific to them as individuals, was personal to them and thereby valorised their identity and effort, and finally, was a personal response from the lecturer, which was interpreted as sincerity. Second, the feedback, and lecturer, was perceived as supportive, caring and motivating. Third, affordances of the media, including the rich cues, resulted in a strong sense that the feedback was clear, detailed and unambiguous. Fourth, students reported that the video-based feedback resulted in reflecting on their task performance, process and thinking. Fifth, students not only perceived the feedback to be constructive, but they also used the feedback to devise future strategies.

This article has proposed some explanations of these themes. However, further research needs to be conducted to understand the complex relationship between the affordances of the media itself, the process of recording (e.g., length, framing, unscripted nature), structure of the feedback (Table 2), and the adopted eight principles of feedback. In addition, this article has taken a grounded approach to identifying perceived strengths and weaknesses, but future research needs to account for impact on learning, selfefficacy beliefs and future task performance. This includes measuring the degree of redundancy in the feedback content; validating the usefulness of the high volumes of detail. In addition, the researchers are currently engaged in research investigating the implications of context, including class size, discipline, and assessment type (e.g., formative). We are also exploring the use of the feedback principles, and feedback structure (Table 2) with different modes (e.g., screencasting) and combinations of modes (e.g., video and text annotations). We are also seeing an increasing need to engage in a large-scale experimental design to compare text and audiovisual feedback.

Despite the many questions still unanswered, the positive reaction to video-based feedback by both students and lecturers, combined with the observation that the effort of creating these videos is a sustainable work practice, strongly encourages us to continue experimenting. There is, however, one problem raised by a student that we feel may be unresolvable: "Only problem is - how can I stick it on the fridge!?”

\section{References}

Abrahamson, E. (2010). Enhancing students' understanding of formative assessment through videofeedback on an undergraduate sports rehabilitation programme. Oxford: The Higher Education Academy. Retrieved from http://wwwnew1.heacademy.ac.uk/assets/hlst/documents/case_studies/147_abrahamson_video-feedback.pdf

Bailey, R., \& Garner, M. (2010). Is the feedback in higher education assessment worth the paper it is written on? Teachers' reflections on their practices. Teaching in Higher Education, 15(2), 187-198. doi:10.1080/13562511003620019

Bellini, S., \& Akullian, J. (2007). A meta-analysis of video modeling and video self-modeling interventions for children and adolescents with autism spectrum disorders. Exceptional Children, 73(3), 264-287. doi:10.1177/001440290707300301

Biggs, J. B. (2003). Teaching for quality learning at university: What the student does. Maidenhead: Society for Research into Higher Education \& Open University Press.

Boud, D. (2000). Sustainable assessment: Rethinking assessment for a learning society. Studies in Continuing Education, 22(2), 151-167. doi:10.1080/713695728

Boud, D., Cohen, R., \& Sampson, J. (1999). Peer learning and assessment. Assessment and Evaluation in Higher Education, 24(4), 413-426. doi:10.1080/0260293990240405

Boud, D., \& Molloy, E. (2013). Feedback in higher and professional education. New York, NY: Routledge. 
Brockbank, A., \& McGill, I. (1998). Facilitating reflective learning in higher education. Buckingham: Society for Research into Higher Education \& Open University.

Brown, S., \& Knight, P. (Eds.). (1994). Assessing learners in higher education. London: Kogan Page.

Cann, A. J. (2007). Podcasting is dead. Long live video! Bioscience Education, 10. doi:10.3108/beej.10.c1j

Costello, J., \& Crane, D. (2010). Providing learner-centered feedback using a variety of technologies. Paper presented at the International Conference on the Liberal Arts, St. Thomas University, Fredericton, New Brunswick. Retrieved from http://w3.stu.ca/stu/academic/departments/social_work/pdfs/CostelloandCrane.pdf

Crisp, B. R. (2007). Is it worth the effort? How feedback influences students' subsequent submission of assessable work. Assessment and Evaluation in Higher Education, 32(5), 571-581. doi:10.1080/02602930601116912

Crook, A., Mauchline, A., Mawc, S., Lawson, C., Drinkwater, R., Lundqvist, K., . . Park, J. (2012). The use of video technology for providing feedback to students: Can it enhance the feedback experience for staff and students? Computers \& Education, 58(1), 386-396. doi:10.1016/j.compedu.2011.08.025

Crook, A., Park, J., Lawson, C., Lundqvist, K., Drinkwater, R., Walsh, J., . . Maw, S. (2010). ASSET: Moving forward through feedback (pp. 1-20). Reading: Univeristy of Reading.

Daft, R. L., \& Lengel, R. H. (1986). Organizational information requirements, media richness and structural design. Management Science, 32(5), 554-571. doi:10.1287/mnsc.32.5.554

Denton, P., Madden, J., Roberts, M., \& Rowe, P. (2008). Students' response to traditional and computerassisted formative feedback: A comparative case study. British Journal of Educational Technology, 39(3), 486-500. doi:10.1111/j.1467-8535.2007.00745.x

Dochy, F., Segers, M., \& Sluijsmans, D. (1999). The use of self-, peer- and co-assessment in higher education: a review. Studies in Higher Education, 24(3), 331-350. doi:10.1080/03075079912331379935

Duncan, N. (2007). 'Feed-forward': Improving students' use of tutors' comments. Assessment and Evaluation in Higher Education, 32(3), 271. doi:10.1080/02602930600896498

Evans, C. (2013). Making sense of assessment feedback in higher education. Review of Educational Research, 83(1), 70-120. doi:10.3102/0034654312474350

Falchikov, N. (1995). Improving feedback to and from students. In P. Knight (Ed.), Assessment for learning in higher education (pp. 157-166). London: Kogan Page.

Gibbs, G., \& Simpson, C. (2004). Conditions under which assessment supports students' learning. Learning and Teaching in Higher Education, 1(1), 3-31. Retrieved from http://insight.glos.ac.uk/tli/resources/lathe/Pages/default.aspx

Hase, S., \& Saenger, H. (1997). Videomail-a personalised approach to providing feedback on assessment to distance learners. Distance Education, 18, 362-369. doi:10.1080/0158791970180211

Hattie, J. A., \& Timperley, H. (2007). The power of feedback. Review of Educational Research, 77(1), 81-112. doi:10.3102/003465430298487

Henderson, M., \& Phillips, M. (2014). Technology enhanced feedback on assessment. Paper presented at the 26th Australian Computers in Eductional Conference 2014, Adelaide, South Australia. Retrieved from http://acec2014.acce.edu.au/session/technology-enhanced-feedback-assessment

Hepplestone, S., Holden, G., Irwin, B., Parkin, H., \& Thorpe, L. (2011). Using technology to encourage student engagement with feedback: A literature review. Research in Learning Technology, 19(2), 117127. doi:10.1080/21567069.2011.586677

Higgins, R., Hartley, P., \& Skelton, A. (2001). Getting the message across: The problem of communicating assessment feedback. Teaching in Higher Education, 6(2), 269-274. Retrieved from http://www.tandfonline.com/toc/cthe20/current\#.VIVRM2SUfiI

Hyde, E. (2013). Talking results - trialing an audio-visual feedback method for e-submissions. Innovative Practice in Higher Education, 1(3). Retrieved from http://journals.staffs.ac.uk/index.php/ipihe/index

Ives, J. C., Straub, W. F., \& Shelley, G. A. (2002). Enhancing athletic performance using digital video in consulting. Journal of Applied Sport Psychology, 14(3), 237-245. doi:10.1080/10413200290103527

Joint Information Systems Committee [JISC]. (2010). Effective assessment in a digital age: A guide to technlogy-enahanced assessment and feedback. Bristol: Higher Education Funding

Council for England. Retrieved from http://www.jisc.ac.uk/media/documents/programmes/elearning/digiassass_eada.pdf

Juwah, D., Macfarlane-Dick, B., Matthew, D., Nicol, D., \& Smith, B. (2004). Enhancing student learning through effective formative feedback. York: The Higher Education Academy.

Lizzio, A., \& Wilson, K. (2008). Feedback on assessment: students' perceptions of quality and 
effectiveness Assessment and Evaluation in Higher Education, 33(3), 263-275. doi:10.1080/02602930701292548

Mathieson, K. (2012). Exploring student perceptions of audiovisual feedback via screencasting in online courses. American Journal of Distance Education, 26(3), 143-156. doi:10.1080/08923647.2012.689166

McConnell, D. (2006). Chapter four: Assessing learning in e-groups and communities. In D. McConnell (Ed.), E-learning groups and communities (pp. 90-123). Maidenhead: Open University Press.

Nicol, D., \& Macfarlane-Dick, D. (2006). Formative assessment and self-regulated learning: A model and seven principles of good feedback practice. Studies in Higher Education, 31(2), 199-218. doi:10.1080/03075070600572090

Orsmond, P., \& Merry, S. (2011). Feedback alignment: effective and ineffective links between tutors' and students' understanding of coursework feedback Assessment and Evaluation in Higher Education, 36(2), 125-136. doi:10.1080/02602930903201651

Parton, B. S., Crain-Dorough, M., \& Hancock, R. (2010). Using flip camcorders to create video feedback: Is it realistic for professors and beneficial to students? International Journal of Instructional Technology \& Distance Learning, 7(1), 15-23. Retrieved from http://www.itdl.org/

Race, P., Brown, S., \& Smith, B. (2005). 500 tips on assessment (2nd ed.). Abingdon: RoutledgeFalmer.

Sadler, D. R. (1989). Formative assessment and the design of instructional systems. Instructional Science, 18, 119-144. doi:10.1007/BF00117714

Short, J., Williams, E., \& Christie, B. (1976). The social psychology of telecommunications. London: John Wiley and Sons.

Stefani, L. A. J. (1994). Peer, self and tutor assessment: relative reliabilities. Studies in Higher Education, 19(1), 69-75. doi:10.1080/03075079412331382153

Corresponding author: Michael Henderson, michael.henderson@monash.edu

Australasian Journal of Educational Technology (C) 2015.

Please cite as: Henderson, M., and Phillips, M. (2015).Video-based feedback on student assessment: scarily personal. Australasian Journal of Educational Technology, 31(1), 51-66. 